\title{
DIGITAL ASSESSMENTS
}

\author{
Kurt Gammelgaard Nielsen ${ }^{1}$, Lise Petersen ${ }^{2}$ \\ 1-2University of Southern Denmark, IT-service, Campusvej 55, 5230 Odense M, Denmark \\ Email Address: kgn@sdu.dk
}

\section{Digital assessments}

In accordance with The Danish eGOVERNMENT strategy 2011-2015 digital assessment and exam should be implemented at all Danish universities by the end of $2013^{1}$. University of Southern Denmark (SDU) decided to start the implementation in May 2010.

By the exam term of January 2013, the implementation proved successful, and close to completion. The majority of assessments at all of the 5 faculties and 5 campuses were digital, and students had handed in a total of 17.021 digital assessments ${ }^{2}$.

On the basis of a conscious approach to active learning and activating teaching as well as E-learning, SDU has implemented digital assessments. There are many models in use at SDU, but since there is not just one model and one way to assess students a broad selection of IT-tools has been developed: multiple choice questionnaire (MCQ-test), e-Portfolios2, exam with internet access, exam with some internet access.

In this paper 2 tools will be presented:

SDU Scribble, a reporting software with digital pen and text editor functionality, and

Innotour.com, a WEB 2.0 platform for education, research and business development in tourism

\section{Pedagogy}

We here describe two digital learning tools, developed at University of Southern Denmark, SDU Scribble and Innotour (see later). Rather than being new pedagogy both of them represent an innovative approach to support and promote learning in a digital way. Students and teachers can be truly digital in teaching and learning as well as during exams, while fulfilling the University of Southern Demarks principle of Active Learning and Activating Teaching ${ }^{3}$.

The intention of the tools developed is to support existing didactic principles and allow known learning activities to become digital, thereby releasing resources for the teaching and learning process. Moreover, the digitalization of communication between students and lecturer and in between students can make communication and interaction far easier and save time - thereby promoting it.No more pieces of paper with drawings and notes lying around - everything is digital right from the beginning, and can be shared, send to someone for comments, modified, transferred to other documents.

In SDU Scribble, assessment and feedback is supported with workflow functionality that support communication between lecturer and student on assignments. The lecturer can open an assignment, comment on it with typed text or handwritten notes, and send it directly to the student without time-consuming upload-download operations. The student will be able to access the feedback in context with his/her own work at all times - thereby getting the maximal benefit from it.

Both tools facilitate he collaborative learning process by allowing all information to be kept online at all times. The result is a highly accessable information flow, that supports innovation and knowledge creation.

\footnotetext{
${ }^{1}$ The Danish eGoverment strategy 2011-2015

${ }^{2}$ Number of digital assignments handed in by students pr. Month http://webhotel.sdu.dk/prod/assignmentstats/

${ }^{3}$ http://www.sdu.dk/en/om_sdu/organisationen/destuderendeicentrum/programmer+og+projekter/stud-I \%c3\%a6ring/b\%c3\%a6rende+principper
} 


\section{SDU Scribble}

SDU Scribble is a software that can be downloaded to the students own PC. http://Scribble.sdu.dk. With SDU Scribble the student are able to include handwriting (formulas, symbols, phonetics, Greek, Arab, Chinese etc.) and drawing (chemical structures, anatomic sketches, construction sketches etc.) as a natural part of academic reports and assignments.

Numerous digital pens and useful software already exist on the market, but none of them are compatible with all of the three platforms that our students use: Windows, Mac and Linux. At SDU, there is a demand for a system that provides the same user experience, regardless of the platform used.

Furthermore, workflow functionality is being developed, to support the entire process before, during and after exams/assessments. Thereby also feedback is promoted - the lecturer will be able to write the feedback directly in a student paper, and return the annotated document to the student by e-mail directly from the SDU Scribble menu.

SDU Scribble was implemented broadly at Faculty of Science during the autumn 2012. At Faculty of Science SDU Scribble has been used in exams with app. 1000 students since summer 2012, including mathematics, physics, organic chemistry, biochemistry and molecular biology.

At the Faculty of Science it is up to the students to choose their tool for making digital handwriting and drawings, for instance a scanner (or smartphone with scanner software) or different digital pen solutions optional. Mathematics software like Maple or Matlab can be used in some situations.

At the Medical School implementation of SDU Scribble started in January 2013. The medical students work with report writing in a slightly different way than the science students. For instance mathematics software is used very little by medical students, but they very often need to make (anatomic or molecular structure) drawings, comment on existing images/drawings, and also need to write formulas by hand and work with images, for instance $x$-rays a.o.

What can SDU Scribble do for university teaching and learning?

A few examples:

\section{Weekly lab reports in a General Chemistry course}

- Description of the lab exercise is provided by the teacher in .pdf format, including sketches of the experimentel setup, and tables for experimental data

- The student opens the .pdf in SDU Scribble, and is now able to add his/her data to the table by handwriting, describe observations by typing/handwriting, include handwritten calculations (incl. formulas) and chemical reactions, and write

- conclusions by typing/handwriting. Finally, the report is handed in to the e-learning platform, from the Scribble menu

- The teacher downloads the file, opens it in SDU Scribble, and adds notes and supplementary drawings to the document. The annotated report is returned to the student by e-mail, from the Scribble menu.

\section{Exam in Mathematics - handwriting only}

- $\quad$ The exam questions are provided by the teacher in .pdf-format.

- The student opens the .pdf in Scribble, chooses Online Mode, adds a blank page, attaches the base unit to a piece of paper and starts writing - everything written on the paper now appears on screen. Finally, the assignment is handed in to the e-learning platform from the Scribble menu.

- The teacher downloads the file, opens it in SDU Scribble, and makes his notes in the document. The annotated file is sent to archive, directly from the Scribble menu.

\section{INNOTOUR}

INNOTOUR (website: http://innotour.com ) is a WEB 2.0 platform for education, research and business development in tourism. INNOTOUR is an experimental meeting place for academics, students and enterprises.

Innotour was developed to support a cross-border education: The European Master in Tourism Management (EMTM), a collaboration between the University of Ljubliana, Slovenia, the University of 
Girona, Spain, and SDU in an Erasmus Mundus accredited joint degree.

The learning activities here also support SDUs principle of active learning. Inside INNOTOUR you will find wiki, blogs, video and collaboration tools, all to support innovation e.g. an interactive "innovation ability test". Innotour is directed towards companies, but can also be used by students in their assessments and learning activities. One example is the Innotours "risk assessment test" which is based on theory and research in business and social economics. The platform can be used in the classroom as well as in connection with problem solving.

The platform did not only support course activates, but also made teachers to think new tools of assessments.

"Not only is it important that assessment focuses on the process rather than solely valuing the end result, it is also essential that part of the evaluation procedure becomes the responsibility of the participants. This could be in the form of peer review, for example, based upon comments from fellow students, constructive criticism during the process, and so on." (Liburd,2011, p.119)

So for the last 4 years, SDU held more than 30 oral candidate defense and other oral examinations via web-conference system. The reason for the spread of oral examination at SDU is first and foremost an increasing practical need to conduct oral examinations live, online over the distance. For the parties involved, ie. supervisor, examiner and studentsweb-conference systems seem to provide users with a substantial and attractive flexibility in terms of saving time and travel costs. Students, supervisors and examiners all have had very positive experiences with attending live online examinations. Some examiners have been skeptical, but after examination they have been surprised by how easy it was to establish a social presence in the virtual meeting room. In addition, examiners are excited about the flexibility that the possibility provides. Many examiners can complete examination of a candidate defense directly from their workplace or home, and thereby remove the travel time. Furthermore, digital oral exam also:

"... places significant demands on the established educational system to renew and not least accept the idea that students should have a greater role in evaluating, learning and assessment." (Liburd,2011, .p.119)

The experience from these exams also have impacton other exam. When introducing digital exams education institutions are facing intuitional challenges from examiners, students and teachers. In cross boarder education one has to address this across the institutions involved in these courses.

\section{References}

Liburd, J., Hjalager,A, Christensen, I (2011), Valuing Tourism Education 2.0, Journal of Teaching in Travel \& Tourism, 11:107-130, 2011

The Danish eGoverment strategy 2011-2015

Downloadsite for SDU Scribble: SDU Scribble 